\title{
QUESTÕES DEONTOLÓGICAS E DE METODOLOGIA DE INVESTIGAÇÃO EM SOCIOLOGIA O caso do interesse público e das profissões
}

\author{
Luísa Veloso \\ Instituto Universitário de Lisboa (ISCTE-IUL), CIES-IUL, Lisboa, Portugal \\ João Freire \\ Instituto Universitário de Lisboa (ISCTE-IUL), CIES-IUL, Lisboa, Portugal \\ Luísa Oliveira \\ Instituto Universitário de Lisboa (ISCTE-IUL), CIES-IUL, Lisboa, Portugal \\ Noémia Lopes \\ Instituto Superior de Ciências da Saúde Egas Moniz, ESSEM; \\ Instituto Universitário de Lisboa (ISCTE-IUL), CIES-IUL, Lisboa, Portugal
}

\section{Introdução}

O texto que segue tem como objetivo refletir sobre um conjunto de questões deontológicas, e também teórico-metodológicas, que se colocam aos sociólogos no caso particular das investigações que realizam sobre as profissões e sobre o associativismo profissional.

O ponto de partida desta reflexão foi um estudo realizado no ano de 2008 na área das profissões da saúde e enquadra-se numa reflexão mais ampla sobre o exercício profissional dos sociólogos.

A profissão de sociólogo é dotada de uma capacidade de realização de estudos no quadro da prestação de provas académicas, no âmbito de instituições de investigação e desenvolvimento (I\&D) a partir de concursos e financiamentos públicos nacionais e comunitários, e ainda em termos de prestação de serviços contratados por entidades públicas ou privadas. É uma atividade de base científica, com um conjunto de princípios de deontologia profissional e um sentido societário de agremiação, não essencialmente virada sobre si mesma, mas porque procura discutir entre pares questões de análise e interpretação da vida social e das suas dinâmicas.

De entre a multiplicidade dos objetos de estudo da sociologia figuram as investigações sobre profissões altamente qualificadas, com base em estudos superiores e certificação por diplomas e títulos académicos e profissionais, à partida colocadas no mesmo patamar de consideração social (e legal) em que se situam os próprios sociólogos. Neste domínio, com acuidade, levantam-se problemas metodológicos específicos, que tocam a legitimidade dos seus saberes e aplicações, sempre que uma determinada atividade ou grupo profissional, como objeto de estudo, é sujeito, explícita ou implicitamente, a um exercício aprofundado de penetração no seu próprio microuniverso, com avaliação das suas competências ou desempenhos, monograficamente ou em confronto com terceiros, isto é, com as chamadas "profissões vizinhas". 
Em Portugal, esta questão colocou-se com maior premência desde fevereiro de 2008, por força de um diploma legal da Assembleia da República (Lei n.․ㅜ를 de 13 de fevereiro) que "estabelece o regime jurídico de criação, organização e financiamento de novas associações públicas profissionais" (n.. 1 do art. $1 .^{\circ}$ ). A questão do associativismo profissional é uma das dimensões estruturantes das profissões qualificadas. Do ponto de vista legal, a constituição de associações públicas profissionais deve assumir um caráter "excecional" e tem lugar apenas "quando a regulação da profissão envolver um interesse público de especial relevo que o Estado não deva prosseguir por si próprio" e desde que sejam "sujeitas ao controlo do respetivo acesso e exercício, à elaboração de normas técnicas e deonto-

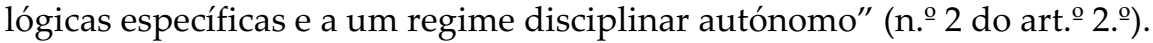

Uma das prescrições estabelecidas por esta legislação encontra-se no n. 3 do art. ${ }^{\circ}$.. , que exige um "estudo elaborado por entidade de reconhecida independência e mérito" sobre a necessidade de criação de associações públicas profissionais, sendo acentuada a "realização do interesse público" e "o seu impacto sobre a regulação da profissão em causa". Na ausência de outras especificações legais ou regulamentares, pressupõe-se que cabe ao grupo profissional interessado em ser reconhecido como associação profissional pública (geralmente designada por "Ordem dos...") solicitar a entidade idónea a realização dessa tarefa, cujo resultado será por ele encaminhado, com outras peças do processo, para a Assembleia da República, órgão de soberania com competência legal para tomar tal decisão.

É a partir da experiência de realização de vários estudos elaborados com este objetivo e, logo, com financiamento privado, que a equipa se propõe refletir sobre algumas questões do foro deontológico e, complementarmente, de âmbito teórico-metodológico, que se colocam à investigação sociológica sobre as profissões e sobre o associativismo profissional.

\section{Investigação e avaliação}

Na investigação sociológica de escala "micro" é muitas vezes impossível evitar a identificação e denominação pública dos sujeitos investigados, sejam eles pessoas físicas ou morais. E quando a análise não é apenas descritiva mas reveste também caráter avaliativo, aumenta concomitantemente a suscetibilidade da operação, pois um dos principais problemas do exercício de avaliação - seja ele um estudo, um parecer ou um instrumento de decisão - radica no facto de daí decorrerem consequências tangíveis, individuais ou coletivas, tais como o emprego, a remuneração e respetivas condições de exercício profissional, o desenvolvimento de uma carreira ou mesmo o prestígio social de um grupo ou instituição.

O que a legislação já referida procura obter é, de facto, uma legitimação científica para este exercício de avaliação, ao exigir a apresentação de um estudo que possa justificar a criação de uma associação pública profissional numa determinada área de atividade. Subjacente a este propósito parece estar, também, a preocupação em garantir a defesa do interesse público, como forma de contornar o risco da 
existência de práticas profissionais que sobreponham algum tipo de interesses particulares ao "interesse geral" da comunidade (Saks, 1995). A questão que se coloca é, neste sentido, a da conciliação da organização corporativa de uma atividade profissional (contemplando, nomeadamente, o reconhecimento público do monopólio do saber, a sua legitimação, o fechamento do mercado de trabalho e a prossecução de interesses corporativos associados) com a realização do interesse público, numa sociedade democrática fundada em valores de liberdade, igualdade de oportunidades e cidadania.

Convém, desde já, sublinhar a ambiguidade que existe na própria letra da lei, ao basear a constituição de uma associação pública profissional na existência e necessidade de salvaguarda de um interesse público, quando este último não está definido em concreto. Na realidade, são muitas as atividades profissionais que poderiam pretender ser providas de "interesse público de especial relevo". As profissões do setor da saúde (Carapinheiro, 1993; Lopes, 2001; Veloso, 2008), das ciências da vida (Gonçalves e Freire, 2009) ou das ciências da Terra encaixam quase certamente nesta definição meramente enunciativa. Foi nelas que os autores tiveram que enfrentar problemas como os que aqui colocamos. Porém, estes problemas são generalizáveis a todos os grupos profissionais que possam ser objeto deste tipo de estudos e interessam assim a uma larga gama de sociólogos.

A preocupação com a avaliação e, concomitantemente, com os riscos subjacentes à avaliação intrapares, conduziu a que, tanto em organismos públicos como em corporações fortemente organizadas, tivessem sido implementadas três tipos de soluções para obviar estes inconvenientes e permitir uma "autoavaliação" profissional eficiente: $1 . \stackrel{a}{\text {, }}$ a constituição de uma hierarquização profissional bem marcada, com categorias diferenciadas que distinguissem as diferentes funções e as relações de autoridade-dependência no âmbito de um determinado domínio de saberes da comunidade profissional, de que são exemplos os casos dos juízes e dos corpos militares (Freire, 2003); 2. ․ a criação de um corpo separado de "inspetores", constituído a partir de elementos selecionados (por concurso, visando identificar os melhor capacitados para a função), de entre os membros da profissão em causa (aplicou-se este modelo, por exemplo, aos serviços públicos de finanças, às carreiras dos ferroviários ou no sistema de ensino obrigatório); 3. a , a existência de uma sucessão de provas individuais avaliadas por júris constituídos por membros da profissão formalmente mais qualificados, que é o que acontece nas carreiras universitárias ou nos concursos para o provimento de lugares de chefia na medicina pública hospitalar (Carapinheiro, 1993). Em qualquer um destes casos, porém, não estava necessariamente em questão a garantia do interesse público, mas antes a eficiência e o rigor de uma avaliação profissional isenta das pressões pessoais, compadrios e despotismos. Tratava-se, sim, de controlar a situação de se estar perante uma pertença comum de avaliadores e avaliados à mesma comunidade profissional, evitando as promiscuidades corporativas.

Quando está em causa a realização de estudos sociológicos sobre as profissões e o associativismo profissional, os "avaliados" pertencem a uma profissão determinada (ou quase-profissão, ou profissão em vias de "proletarização", etc.) e os "avaliadores" a uma outra - a dos sociólogos - , o que constitui uma 
circunstância problemática em termos da legitimação do exercício profissional destes segundos atores. Esta questão coloca-se com mais acuidade quando os resultados da análise realizada não correspondem totalmente às expectativas dos primeiros, designadamente no tocante à delimitação e fronteiras da comunidade profissional, às competências detidas e exigidas no âmbito de perfis profissionais determinados e, ainda, porventura quando são questionados alguns elementos constitutivos da sua identidade profissional.

É neste sentido que os sociólogos, na qualidade de investigadores, devem equacionar e explicitar as condições deste seu desempenho profissional.

\section{Profissões e associativismo profissional}

A reflexão sobre o tema que norteia o presente texto convoca, necessariamente, uma breve resenha inicial sobre a relação umbilical entre profissões e associativismo, de modo a clarificar, não apenas a relevância sociológica do associativismo na construção das profissões, mas sobretudo os desafios éticos, metodológicos e teóricos que hoje se colocam aos sociólogos, quando solicitados para colocarem o seu saber ao serviço da "credenciação social" das eventuais estratégias de fechamento social dos grupos ocupacionais num dado campo profissional.

Tal reflexão assume tanto mais acuidade quanto é verdade o associativismo profissional ter vindo a ser objeto de um crescente investimento nos universos ocupacionais (Freire, 2004), designadamente na sequência das recentes mudanças operadas no sistema de ensino superior e dos efeitos que daí advêm no reposicionamento de muitos grupos ocupacionais, tornando pertinente o fenómeno da professionalization of everyone, parafraseado do título do clássico artigo de Wilensky (1964).

É na senda deste conjunto de questões que seguidamente se sistematizam os eixos sociológicos que mais diretamente podem contribuir para a discussão pretendida.

\section{Associativismo e legitimação do exercício profissional}

As diversas formas de associativismo ocupacional constituem, à luz da sociologia das profissões, manifestações do modelo de exercício do profissionalismo e da sua ideologia (Larson, 1977). Efetivamente, as associações comportam uma "instrumentalidade ontológica" na gestação social das profissões; ou seja, são, em si, uma das condições constitutivas do percurso de fechamento social de qualquer grupo ocupacional - quer pela via da construção identitária, quer pelas modalidades de autorregulação a que as ocupações podem aceder (Moreira, 1997). Contudo, as possibilidades de autorregulação que as associações representam são algo estruturalmente condicionado pelo seu próprio estatuto jurídico. Faz então aqui todo o sentido a distinção entre associações privadas e associações públicas (Rodrigues e Carvalho, 2004). São estas últimas - as associações públicas aquelas que estão em questão nesta nossa reflexão, pois são as que, por via da autoridade legal que lhe é delegada pelo estado, conduzem à criação dos monopólios 
profissionais. O distintivo instrumental das associações públicas é a sua orientação para alcançar monopólios profissionais indissociáveis da autonomia funcional, ou do monopólio da prática (para usar os termos de Freidson, 1986; 1994). Estamos a falar das ordens profissionais.

As ordens profissionais, como associações públicas, asseguram um conjunto de funções que importa destacar: definem as normas e regras práticas e morais do exercício profissional, tendo o poder legal para impor a sua observância e para exercer o respetivo controlo e sancionamento disciplinar; asseguram o monopólio do mercado, no sentido em que determinam as condições de acesso ao exercício profissional, tradicionalmente através da obrigatoriedade de inscrição na própria ordem para exercer a profissão, atualmente também pela via da acreditação dos cursos de ensino superior que dão acesso ao exercício profissional. Esta última questão, que reporta ao sistema de ensino superior, afigura-se como uma dimensão incontornável para a compreensão dos modelos de profissionalismo (Oliveira e Gordinho, 2008; Lopes, 2006). Estes estão, presentemente, a dar lugar à expansão do associativismo profissional em Portugal.

Como já foi referido, na questão da constituição de novas associações públicas, o que está em discussão nos estudos solicitados aos sociólogos neste domínio é demonstrar se os interesses privados (corporativos da profissão) e o interesse público são coincidentes. De alguma forma, está em questão analisar até que ponto a concretização dos interesses privados é uma condição benéfica e potenciadora para assegurar o interesse público. Porventura, é neste particular que a interpelação da dimensão ética do trabalho sociológico mais se salienta, e que a questão dos usos sociais da ciência, e respetiva reflexão crítica, assume renovada pertinência.

\section{Profissionalização e estratégias de associativismo}

Para entender o crescimento recente das estratégias de profissionalização e da luta ocupacional pela constituição de ordens profissionais, importa retomar a questão do ensino. Tradicionalmente, o sistema de ensino superior tem constituído a plataforma incontornável para assegurar a credenciação dos saberes profissionais. Paralelamente, as ordens profissionais têm exercido o seu controlo (direta ou indiretamente) sobre os conteúdos dessa formação e sobre os requisitos necessários para a sua credenciação profissional. Esta estreita relação entre os dois sistemas de credenciação tem criado condições para o que alguns autores têm considerado como "um fechamento profissional em círculo vicioso" (Rodrigues e Carvalho, 2004), o qual pode constituir uma das formas perversas, e porventura questionáveis em contextos de regulação transparente, de alimentar formas de corporativismo indesejáveis para o interesse público.

Em Portugal, como, de algum modo, por toda a Europa, a democratização do acesso ao ensino superior, a integração de formações académicas intermédias em graus de licenciatura e as equivalências formativas que o "modelo de Bolonha" introduziu deram lugar à emergência de estratégias de reposicionamento ocupacional em campos profissionais historicamente afastados da ideologia do profissionalismo. Um fenómeno não marginal para o entendimento destas estratégias é também a 
expansão do ensino superior privado, por via da densidade demográfica que começou a produzir em alguns setores ocupacionais, e o consequente efeito "de pressão" para o fechamento do mercado de trabalho aos não detentores dos títulos académicos ou aos mais recentes destes titulares. Neste sentido, o associativismo profissional assume aqui um renovado protagonismo, quer no sentido do "fechamento", quer da "luta pela inclusão", ou ainda pelo reconhecimento de uma profissão diferenciada na especialização.

Se a tradicional cisão no sistema de ensino superior entre carreiras técnicas e carreiras científicas garantiu durante toda uma época uma espécie de ascendente pericial aos licenciados da universidade que assegurava a manutenção "socialmente pacífica" das fronteiras ocupacionais, presentemente o cenário é distinto: mais do que antes, as disputas sobre as fronteiras "territoriais" das profissões num mesmo campo ocupacional são intensas. O fechamento lateral, ou seja, a exclusão e/ou subordinação de outros grupos ocupacionais que intervêm em áreas contíguas ou comuns é uma das estratégias que mais frequentemente estão em causa.

A questão do sistema de ensino superior merece uma reflexão um pouco mais detalhada, pois tem sido objeto de transformações muito importantes em Portugal, com consequências ainda não totalmente visíveis no mercado de trabalho. Na realidade, a pesquisa sobre a comparabilidade dos curricula de formação de duas ou mais "profissões vizinhas" ganha novos contornos face à reestruturação das licenciaturas segundo os princípios da "Declaração de Bolonha", pelo menos nesta fase de transição. Uma das mudanças ocorridas radica no facto de determinadas atividades profissionais a que se acedia através dos designados "cursos técnicos" (mais tarde, bacharelatos do ensino politécnico), e que se diferenciavam das licenciaturas por terem uma duração mais pequena, passam a ser equivalentes, não só em termos de duração, como também em termos de possibilidades de creditação das unidades curriculares constitutivas de cada licenciatura. No caso português, a situação poderá ser ainda mais complexa, dada a pluralidade dos títulos das licenciaturas que, por razões de concorrência entre as instituições de ensino superior (público e privado), foram proliferando ao longo de duas ou três décadas. E se, por esta via, não houver critérios suficientemente consistentes (do ponto de vista das competências, das funções, etc.) para diferenciar grupos profissionais, o problema pode tornar-se ainda mais complexo. Esta questão assume ainda uma problematização acrescida se nos debruçarmos sobre os mercados de trabalho, nos quais se começam a desenhar tendências para grupos profissionais distintos exercerem as suas atividades nos mesmos segmentos profissionais e, logo, disputarem as mesmas oportunidades de mercado. Pode, neste sentido, formular-se a hipótese segundo a qual o interesse do grupo profissional que acionou o processo para se constituir em ordem profissional visar, justamente, fechar o mercado de trabalho (Paradeise, 1985; 1987), no sentido de excluir os grupos rivais.

É neste contexto que assume toda a relevância a questão da deslocação do enfoque sobre a profissão, ou grupo profissional, para o enfoque sobre o campo profissional. E é justamente aqui que se pode criar um foco de tensão entre os sociólogos (investigadores) e os seus "clientes", porque desde logo se desfoca a esperada atenção exclusiva dos analistas sobre o grupo para um "espaço" mais alargado, 
delimitado, nomeadamente, pelos jogos combinados dos desenvolvimentos técnicos e das relações económicas presentes num determinado domínio, a que se vem juntar a exigência de um interesse público que antes procura corresponder a interesses de comunidades sociais amplas, indiferenciadas e inorgânicas (utentes, consumidores, residentes, cidadãos, etc.).

\section{Da profissão ao campo profissional}

O dilema que se coloca aos sociólogos que, na sua tarefa de prestarem serviços à comunidade como investigadores, assumem o compromisso de estudar um grupo profissional que aspira a tornar-se profissão, para além de colocar as questões já referidas, radica na preocupação em elaborar um estudo "neutro", isto é, não necessariamente orientado pela preocupação de legitimar a jurisdição de um determinado grupo profissional conferindo-lhe o monopólio dessa jurisdição. É, neste sentido, fundamental atender à existência de grupos profissionais vizinhos, sabendo que o critério central de definição dessa "vizinhança" radica na expertise (knowledge) que pode ser detida, no todo ou em parte, por outros grupos profissionais. As exigências teórico-metodológicas que a atividade sociológica impõe traduzem-se na realização de um estudo que, neste caso, se consubstancia na formulação de um objeto de investigação que se enquadre na sociologia das profissões. Frequentemente, os grupos profissionais que aspiram à constituição de uma ordem profissional, perspetivam-se como profissões en train de se faire. E sendo uma obrigatoriedade legal a elaboração de um estudo que assevere (ou não) a necessidade de criação de uma associação pública profissional que zele pelo interesse público, a investigação (e, logo, a atividade e a análise realizada pelos sociólogos) passa necessariamente a ser parte integrante do processo de construção social dessa profissão.

Assumimos aqui o postulado de Abbott (1988), que nos parece incontornável, segundo o qual as profissões existem no conjunto de um sistema ocupacional e não apenas como entidades isoladas, pelo que a sua abordagem deve considerar o sistema de interdependências que caracteriza as relações entre os grupos profissionais. E que as disputas, os conflitos e a competição em torno das áreas jurisdicionais constituem a dinâmica de desenvolvimento de cada profissão. Partindo deste princípio, o objeto de estudo deixa, como foi referido, de incidir sobre o grupo profissional que encomendou o estudo para passar a ser o campo profissional onde diferentes grupos profissionais disputam a mesma área de jurisdição. Neste sentido, cabe ao sociólogo tomar como ponto de partida para a investigação todos os grupos profissionais que operam num determinado campo profissional.

Optar por uma análise centrada no campo profissional constitui, do nosso ponto de vista, uma opção teórica estruturante de um estudo sobre um grupo profissional determinado. Assim, optamos por uma análise do campo profissional, identificando e delimitando os grupos profissionais que mantêm relações de "vizinhança direta" relativamente ao primeiro, com base, em particular, em três dimensões, a saber: oferta formativa ao nível do ensino superior (universitário e politécnico) e respetivas especialidades técnicas e científicas; mercado de trabalho 
e exercício profissional (tanto no espaço empresarial como na administração pública e prestação de serviços como profissão liberal); e universo associativo incluindo as eventuais componentes internacionais que possam aqui ter interferência.

\section{Os sociólogos como investigadores: opções deontológicas e teórico-metodológicas}

Ao longo deste texto foram sendo equacionadas as questões que se colocam aos sociólogos como investigadores/avaliadores quando realizam estudos que, para além de serem encomendados e pagos por uma entidade particular, têm um papel importante na construção social da profissão em causa.

É também sabido como a maior difusão e relevância dos resultados da investigação nas ciências sociais têm tido como consequência a tentação de uma apropriação legitimadora dos interesses materiais e simbólicos, não apenas por parte de entidades económicas e sociais privadas, mas igualmente por parte de instituições públicas e dos órgãos de comunicação de massas.

Assumindo uma postura de rigor teórico-metodológico e de assunção de uma postura pautada por princípios de deontologia profissional, é fundamental manter e enriquecer uma reflexão neste domínio. Trata-se de equacionar o desempenho profissional dos sociólogos procurando, nomeadamente, desenvolver práticas como as seguintes.

A primeira radica em acionar mecanismos de reflexão e de definição de pressupostos de partida, de modo a salvaguardar o exercício da sua profissão como investigadores, pautada por princípios de deontologia e de rigor científicos. É fundamental enfatizar as práticas de excelência e condenar as práticas de produção de conhecimento não isentas de convicções pessoais. Por exemplo, será porventura desejável caminhar metodologicamente para um processo de apuramento das conclusões de uma investigação através do modelo de "prova e contraprova", isto é, de verificar se, com os mesmos dados, não é possível construir uma conclusão diferente, ou até oposta, à primeira que foi extraída pelos investigadores.

A segunda assenta na preocupação em formular muito cuidadosamente o contrato de pesquisa entre "avaliadores" e "avaliados", que estabelece a concessão de um projeto de investigação sociológica. A clareza e explicitação do objeto (teoricamente sustentado) e dos objetivos do estudo (que devem ser atingidos nas suas conclusões), assim como da estratégia metodológica a acionar (técnicas a utilizar, populações a inquirir, etc.) e as condições (prazos, recursos necessários, etc.) em que a pesquisa vai ser desenvolvida podem resultar num grande benefício final, esclarecendo exatamente o que pretende a entidade contratante e evitando as falsas expectativas - quantas vezes multiplicadas pela urgência com que tais procedimentos tendem a ser efetuados.

A terceira condensa pequenas técnicas que podem ser incorporadas nos processos de trabalho da equipa de pesquisa, capazes de melhorar a vigilância crítica 
sobre a qualidade do processo de produção de conhecimentos. Uma delas, já por nós ensaiada, consiste numa fase prévia do projeto em que cada um dos investigadores procede a uma autorreflexão sobre os sentimentos, apriorismos e opiniões que professa acerca do objeto do estudo (e dos agentes nele envolvidos) que vai começar a ser investigado. Esta clarificação (uma espécie de "declaração de interesses" ideológico-afetivos de partida), realizada em reunião apropriada da equipa de investigação, pode constituir um útil dispositivo de reflexão e clarificação de possíveis enviesamentos inconscientes dos investigadores. Uma outra "técnica" possível é a de afetar expressamente a um consultor externo a função de contraditor da equipa de investigação, fazendo-o intervir em determinados momento da execução do projeto para criticar da forma mais exigente possível o encaminhamento metodológico que está a ser dado à pesquisa.

Estas constituem algumas das práticas que podem ser acionadas em estudos que assumem esta natureza. No entanto, são questões que se colocam igualmente quando se trata de investigações asseguradas por financiamentos públicos, na medida em que os conflitos e interesses profissionais estão também aí presentes. E é fundamental reter a pressão que os grupos profissionais e as suas instâncias representativas exercem sobre o estado no sentido de garantirem os seus direitos e privilégios. Neste domínio, equaciona-se a questão da relação entre o estado e o mercado, a qual é o ponto de partida da nossa reflexão, pois a constituição de uma associação pública profissional tem na sua base um princípio de delegação de poderes públicos numa instância que também defende interesses corporativos com consequências claras na estruturação dos mercados de trabalho e de bens e serviços.

\section{Referências bibliográficas}

Abbott, Andrew (1988), The System of Professions. An Essay on the Division of Expert Labor, Chicago, The University of Chicago Press.

Carapinheiro, Graça (1993), Saberes e Poderes no Hospital, Porto, Afrontamento.

Freidson, Eliot (1986), Professional Powers. A Study of the Institutionalization of Formal Knowledge, Chicago, The University of Chicago Press.

Freidson, Eliot (1994), Professionalism Reborn. Theory, Prophessy, Policy, Cambridge, Polity Press.

Freire, João (2003), Homens em Fundo Azul Marinho. Ensaio de Observação Sociológica sobre Uma Corporação nos Meados do Século XX: a Armada Portuguesa, Oeiras, Celta Editora.

Freire, João (org.) (2004), Associações Profissionais em Portugal, Oeiras, Celta Editora.

Gonçalves, Maria Eduarda, e João Freire (coords.) (2009), Biologia e Biólogos em Portugal. Ensino, Emprego, Sociedade, Lisboa, A Esfera do Caos.

Larson, Magali S. (1977), The Rise of Professionalism. A Sociological Analysis, Berkeley, University of California Press.

Lopes, Noémia Mendes (2001), Recomposição Profissional da Enfermagem. Estudo Sociológico em Contexto Hospitalar, Lisboa, Quarteto. 
Lopes, Noémia Mendes (2006), “Tecnologias da saúde e novas dinâmicas de profissionalização", em Graça Carapinheiro (org.), Sociologia da Saúde. Estudos e Perspectivas, Coimbra, Pé de Página, pp. 107-134.

Moreira, Vital (1997), Auto-regulação Profissional e Administração Pública, Coimbra, Almedina.

Oliveira, Luísa, e Bruno Gordinho (2008), “New professionalism in the making: the case of informatics engineering in Portugal", comunicação ao 5. ${ }^{\circ}$ Encontro da Rede Europeia de Sociologia das Profissões - Transforming Boundaries, A "New" Professionalism in the Making, Aarhus, Dinamarca.

Paradeise, Catherine (1985), "Rhétorique professionnelle et expertise", Sociologie $d u$ Travail, $1 / 85$, pp. 17-31.

Paradeise, Catherine (1987), “Des savoirs aux compétences: qualification et régulation des marchés du travail", Sociologie du Travail, 1/87, pp. 35-46.

Rodrigues, Maria de Lurdes, e Helena Carvalho (2004), “Entre o público e o privado: associativismo profissional em Portugal", em João Freire (org.), Associações Profissionais em Portugal, Oeiras, Celta Editora, pp. 257-298.

Saks, Mike (1995). Professions and the Public Interest. Medical Power, Altruism and Alternative Medicine, Londres, Routledge.

Veloso, Luísa (coord.) (2008), Nutrição, Dietética e Alimentação. Um Campo Profissional em Construção, Lisboa, CIES-ISCTE, relatório final da investigação.

Wilensky, H. L. (1964), “The professionalization of everyone?", The American Journal of Sociology, LXX (2), pp. 137-158.

Luísa Veloso. Socióloga e investigadora sénior no Instituto Universitário de Lisboa (ISCTE-IUL), CIES-IUL. Investigadora associada do Instituto de Sociologia da Faculdade de Letras da Universidade do Porto. E-mail: luisa.veloso@iscte.pt

João Freire. Sociólogo, professor catedrático aposentado e professor emérito do Instituto Universitário de Lisboa (ISCTE-IUL). Investigador no Centro de Investigação e Estudos de Sociologia (CIES-IUL).

E-mail: joao.freire@mail.telepac.pt

Luísa Oliveira. Professora no Instituto Universitário de Lisboa (ISCTE-IUL) e investigadora no Centro de Investigação e Estudos de Sociologia (CIES-IUL). E-mail: luisa.oliveira@iscte.pt

Noémia Lopes. Professora associada do Instituto Superior de Ciências da Saúde Egas Moniz e da Escola Superior de Saúde Egas Moniz. Investigadora do Instituto Universitário de Lisboa (ISCTE-IUL), Centro de Investigação e Estudos de Sociologia (CIES-IUL). E-mail: nlopes@egasmoniz.edu.pt, noemia.lopes@iscte.pt 


\section{Resumo/ abstract/ résumé/ resumen}

Questões deontológicas e de metodologia de investigação em sociologia: o caso do interesse público e das profissões

O artigo tem como objetivo refletir sobre um conjunto de questões deontológicas e teórico-metodológicas que se colocam aos sociólogos no caso particular das investigações que realizam sobre as profissões e o associativismo profissional. O ponto de partida desta reflexão foi um estudo realizado no ano de 2008 na área das profissões da saúde e enquadra-se numa reflexão mais ampla sobre o exercício profissional dos sociólogos.

Palavras-chave ética de investigação, metodologia, profissões, associações profissionais.

Deontological and methodological questions regarding sociological research: the case of professions and the public interest

The authors' objective in this article is to reflect on a set of deontological and theoretical/methodological questions that face sociologists in the particular case of their research on professionals and professional associations. The starting point for this reflection was a 2008 study on the healthcare professions field, which is considered within the overall framework of some broader thoughts on the way in which sociologists work.

$\underline{\text { Keywords }}$ research ethics, methodology, professions, professional associations.

Questions déontologiques et de méthodologie de recherche en sociologie: le cas de l'intérêt public et des professions

Cet article réfléchit sur un ensemble de questions déontologiques et théorico-méthodologiques auxquelles doivent faire face les sociologues dans le cas particulier des recherches qu'ils mènent sur les professions et les associations professionnelles. Le point de départ de cette réflexion a été une étude menée en 2008 dans le domaine des professions médicales et s'inscrit dans une réflexion plus vaste sur l'exercice professionnel des sociologues.

Mots-clés éthique de recherche, méthodologie, professions, associations professionnelles. 
Cuestiones deontológicas y de metodología de investigación en sociología: el caso del interés público y de las profesiones

El artículo tiene como objetivo reflexionar sobre un conjunto de cuestiones deontológicas y teórico-metodológicas que se ponen a los sociólogos en el caso particular de las investigaciones que realizan sobre las profesiones y el asociativismo profesional. El punto de partida de esta reflexión fue un estudio realizado en el año de 2008 en el área de las profesiones de la salud y se encuadra en una reflexión más amplia sobre el ejercicio profesional de los sociólogos.

Palabras-clave ética de investigación, metodología, profesiones, asociaciones profesionales. 